\title{
COVID-19 vaccine acceptance and associated factors among women attending antenatal and postnatal cares in Central Gondar Zone public hospitals, Northwest Ethiopia
}

\author{
Eden Bishaw Taye ${ }^{\mathrm{a}, *}$, Zewdu Wasie Taye ${ }^{\mathrm{b}}$, Haymanot Alem Muche ${ }^{\mathrm{a}}$, Nuhamin Tesfa Tsega ${ }^{\mathrm{c}}$, \\ Tsion Tadesse Haile ${ }^{\mathrm{d}}$, Agumas Eskezia Tiguh ${ }^{\mathrm{a}}$ \\ ${ }^{a}$ Department of Clinical Midwifery, School of Midwifery, College of Medicine and Health Sciences, University of Gondar, Gondar, Ethiopia \\ ${ }^{\mathrm{b}}$ Organization for Rehabilitations and Development Association Ethiopia, Gondar, Ethiopia \\ ' Department of Women's and Family Health, School of Midwifery, College of Medicine and Health Sciences, University of Gondar, Gondar, Ethiopia \\ ${ }^{\mathrm{d}}$ Department of General Midwifery, School of Midwifery, College of Medicine and Health Sciences, University of Gondar, Gondar, Ethiopia
}

\section{A R T I C L E I N F O}

\section{Keywords:}

COVID-19

Vaccine acceptance

Pregnant and postnatal mothers

Ethiopia

\begin{abstract}
A B S T R A C T
Introduction: The Coronavirus disease 2019 pandemic is a public health problem, which caused a major impact on morbidity and mortality around the world. Even though an effective vaccine is the most awaited resolution for the pandemic, little is known about COVID-19 vaccine acceptance in Ethiopia. This study aimed to assess vaccine acceptance and its associated factors among pregnant and postnatal mothers.

Method: Institution-based cross-sectional study was conducted on 527 pregnant and postnatal mothers from August 15 to September 15, 2021. Data were collected using an interviewer-administered structured questionnaire. A systematic random sampling technique was used to select the study participants. Epi-Data version 4.6 and Stata 16 software were used for data entry and analysis respectively. Participant characteristics and rate of vaccine acceptance were presented using descriptive statistics. Multi-variable logistic regression was performed to identify statistically significant variables. Adjusted odds ratio with $95 \%$ confidence interval was used to declare statistical significance based on $p<0.05$ in the multivariable logistic regression model.

Result: The overall prevalence of intent to accept COVID-19 vaccine was $62.04 \%$ (95\% CI: 57.65, 66.25). Of those $40.08 \%$ were pregnant mothers and $21.97 \%$ of them were postpartum mothers. Urban residence (AOR $=2.03$, 95\% CI: 1.09-3.77), respondents who were worry about COVID-19 disease (AOR = 3.46, 95\% CI: 2.16-5.52), and participants who had favorable attitude towards vaccine (AOR $=8.54,95 \%$ CI: 5.18-14.08) were significantly associated with COVID-19 vaccine acceptance.

Conclusion: Our findings showed that the willingness to accept COVID-19 vaccination was low. Residence, worry about COVID-19 disease, and attitudes towards vaccine were factors significantly associated with COVID-19 vaccine acceptance. Evidence-based and clear information on COVID-19 vaccines should be provided to pregnant and postnatal mothers for both rural and urban residences to improve attitude towards the COVID-19 vaccine and increase vaccination rates.
\end{abstract}

\section{Introduction}

Coronavirus disease 2019 (COVID-19) is a highly contagious respiratory disease caused by a novel coronavirus called severe acute respiratory syndrome coronavirus. ${ }^{1}$ The COVID-19 pandemic is continuing to impose enormous burden of morbidity and mortality while severely disrupting societies, health system and economies worldwide. ${ }^{2}$ World health organization (WHO) reports that confirmed cases of the disease reached more than 228 million by September 19, 2021 and caused more than 4.7 million deaths worldwide. ${ }^{3}$ According to African CDC report, in the continent there were more than 8.3 million confirmed COVID-19 cases and 210,088 deaths by September 21, 2021. ${ }^{4}$ In Ethiopia, COVID-19 causes 365,167 confirmed cases and 6459 deaths by October $31,2021 .{ }^{5}$ Governments must be ready to ensure large-scale, equitable access and distribution of a COVID-19 vaccine if and when a safe and effective one becomes available. ${ }^{2}$

Even though pregnant and lactating women were excluded from

\footnotetext{
* Corresponding author. Po. Box 196, Gondar, Ethiopia.

E-mail address: edbishaw16@gmail.com (E.B. Taye).
} 


\section{Abbreviations}

ACOG American College of Obstetrics and Gynecology

ANC antenatal care

AOR adjusted odds ratio

CDC center for disease control and prevention

CI confidence interval

COR crud odds ratio

COVID-19 Coronavirus disease 2019

ICU intensive care unit

PNC postnatal care

SARS-COV-2 severe acute respiratory syndrome coronavirus

WHO world health organization

initial COVID-19 vaccine trials ${ }^{6}$; Centers for Disease Control and Prevention (CDC) and the American College of Obstetricians and Gynecologists (ACOG) recommended that COVID-19 vaccine should be offered for pregnant women who meet the criteria for vaccination and should be encouraged to talk with their obstetric provider about their vaccination plan. ACOG also recommends that vaccines should be offered to lactating women similar to non-lactating ones when they meet the criteria.

Pregnant women with COVID-19 have a higher risk than similar nonpregnant persons for poor health outcomes and that risks may also be higher for their babies. ${ }^{7}$ COVID-19 infection during pregnancy is associated with increased risk of maternal severe illness, ICU (intensive care unit) admission, mechanical ventilation, and death of the mother. ${ }^{8}$ COVID-19 infection increases the risk of adverse birth outcomes to the fetus such as preterm delivery, cesarean delivery, neonatal admissions to the intensive care unit, and pregnancy loss. ${ }^{8,9}$ According to ACOG, COVID-19 also increases the risk of complications in pregnant and lactating women with underlying health conditions including diabetes, obesity, and cardiovascular disease and those mothers with increasing age. Therefore, pregnant and lactating women should be offered COVID-19 vaccine and be encouraged to take it. ${ }^{7}$

Transmission of the COVID-19 virus can be mitigated through physical distancing, use of face coverings, hand and respiratory hygiene, and avoiding crowds and poorly ventilated spaces ${ }^{10}$ SARS-CoV-2 is a new virus to which the human population has no immunity. ${ }^{11}$ Herd immunity against COVID-19 should be achieved by protecting people through vaccination. The COVID-19 vaccines are expected to provide at least some protection against new virus variants and are effective at preventing serious illness and death as a result of developing an immune response to the SARS-Cov-2. ${ }^{12}$ However, public vaccine hesitancy is a pressing problem for public health authorities. With the availability of COVID-19 vaccines, little information is available on the public acceptability and attitudes towards the COVID-19 vaccines. ${ }^{13}$ ACOG suggested that individuals can receive any product that is made available to them and can be confident in the vaccine's ability to provide a high level of protection from COVID-19-relatede severe illness.

The COVID-19 pandemic is also a particular concern for pregnant and breastfeeding women. ${ }^{14}$ The use of vaccines to protect pregnant women and their newborns from infectious diseases is an integral part of routine obstetric practice. ${ }^{7}$ It is well known that the concept of passive immunization of the newborn obtained with the transplacental passage of protective antibodies into the fetal/neonatal circulation after maternal infection or vaccination of COVID-19 and COVID-19 vaccine-induced IgG pass to the neonates through breast milk. ${ }^{5}$ Therefore, maternal vaccination can protect the mother, fetus, and baby. ${ }^{8}$

Even though vaccines are effective interventions to reduce the burden of COVID-19 disease; public vaccine hesitancy is a pressing problem to deliver the vaccine. ${ }^{13}$ So, evidence-based and tailored information on COVID-19 vaccines should be provided to pregnant and breastfeeding women to avoid unfounded concerns about the vaccines and to support shared decision-making in the population. ${ }^{14}$ The government of Ethiopia had started to deliver the COVID-19 vaccine on March 13, 2021, but there is limited evidence about the acceptance of the vaccine particularly in pregnant and lactating mothers. Therefore, this study aimed to investigate the acceptability of COVID-19 vaccines and the factors associated with acceptance of the COVID-19 vaccine.

\section{Methods and materials}

\subsection{Study design, setting, and period}

A health institution-based cross-sectional study was conducted from August 15 to September 15, 2021. The study was conducted in the Central Gondar Zone of Amhara Regional State, which is located at 748 $\mathrm{Km}$ to Northwest of Addis Ababa. The zone includes 15 woredas, one administration town, and the City of Gondar, which is the capital of the zone. There are six primary hospitals named, Dembia, Aykel, Wogera, Delgi, Arbaya and Guhala, and one public referral hospital named, University of Gondar Compressive and Specialized hospital.

\subsection{Source and study population}

All pregnant and postnatal mothers who came for antenatal and postnatal care in Central Gondar Zone hospitals were the source population. All pregnant and postnatal mothers who came for antenatal and postnatal care in selected Central Gondar Zone hospitals during the data collection period were the study population.

\subsection{Inclusion and exclusion criteria}

All pregnant and postnatal women were included in the study. Pregnant and postnatal women who were seriously ill during the data collection period were excluded.

\subsection{Sample size determination and sampling technique}

The sample size of this study was calculated by using the single population proportion formula.

The sample size calculation formula is as follow:

$n=\frac{\left(\frac{\mathrm{Za}}{2}\right) 2 * \mathrm{P}(1-\mathrm{P})}{\mathrm{w} 2}$

where $\mathrm{P}$ is the sample proportion which is $70.7 \%{ }^{15}$ to take as proportion, $\mathrm{Za} / 2=1.96$ critical value of normal distribution at $\alpha / 2$ at $95 \%$ confidence interval and $5 \%$ marginal error $\left(_{\mathrm{w}}\right)$.

$\mathrm{n}=(1.96)^{2} * 0.707(1-0.707) /(0.05)^{2}=318.316 \approx 319$ and by considering the non-response rate of $10 \%$ and designing effect of 1.5 the final sample size was 527 .

From the seven hospitals, three hospitals, namely, Dembia, Wogera, and University of Gondar Compressive and Specialized hospital were selected using a lottery method. A proportional allocation of the sample to the selected health facilities was made based on the reports of the preceding three months of prenatal and postnatal care attendants, while the systematic sampling technique was used to select the study participants.

\subsection{Terms and operational definitions}

Vaccine acceptance: COVID-19 vaccine acceptance was measured using "Yes" and "No" questions. Respondents were asked "If the vaccine is available for COVID-19 are you willing to take it"; respondents who respond "yes" were given a score of 1 and "No" response was given a score of 0 . Accordingly, respondents who scored 1 were thought of as having an intention to accept the COVID-19 vaccine, and respondents 
who scored 0 were thought of as having no intention to accept the COVID-19 vaccine.

Antenatal care is the routine healthcare of presumed healthy pregnant women without symptoms (screening), to diagnose diseases or complicating obstetric conditions without symptoms, and to provide information about lifestyle, pregnancy, and delivery.

Postnatal care: Care given to the mother and her newborn baby immediately after the birth of the placenta and for the first six weeks of life.

Good knowledge: Participants who responded three and above from five knowledge assessing items about vaccines were labeled as having good knowledge otherwise poor knowledge. Respondents who answered "yes" for knowledge assessing questions were scored 1 and respondents who were answered "no or uncertain" for knowledge assessing questions were scored 0 .

Favorable attitude: Participants who responded three and above from five attitude assessing items about vaccines were labeled as having favorable attitude otherwise unfavorable attitude. Respondents who answered "yes" for attitude assessing questions were scored 1 and respondents who were answered "no or uncertain" for attitude assessing questions were scored 0 .

\subsection{Data collection tools and procedures}

Data were collected from August 15 to September 15, 2021 using a pretested, structured questionnaire. The questionnaire was adapted from different literature. ${ }^{14-17}$ The questionnaire was prepared in English and translated to Amharic and retranslated into English to keep consistency. The study tool was assessed by a group of researchers to check the clarity and completeness. The data were collected from pregnant and postnatal mothers during their ANC and PNC visits respectively. The interviews took place after the participants attended their clinic appointments at their exit time. Data were collected by three trained diploma Midwives and three supervisors provided quality assurance of the data collection process.

\subsection{Quality assurance mechanisms}

All interviewers and supervisors received training on the study procedures, and interviewing techniques. Questionnaires were checked for completeness and consistency daily during the time of data collection and incomplete ones were sent back to the data collector for check-up under supervision. Daily feedback on data collection activities were given by supervisors. Questionnaires were checked for content validity by experts in the field. The questionnaire was pre-tested before the start of actual data collection on $5 \%$ of the total required sample at Debark General Hospital. Accordingly, the clarity, wording, logical sequence, and skip patterns of the questions were amended.

\subsection{Data analysis and presentation}

First, data were checked for completeness, coded, and then entered into EpiData version 4.6 software and exported to Stata version 16 software for analysis. Variables independently associated with COVID19 vaccine acceptance were identified by using multiple logistic regressions and computing an AOR, with $95 \% \mathrm{CI}$ and p-values. Data were organized and presented using tables, graphs, and charts.

\section{Result}

\subsection{Socio-demographic characteristics of the participant}

A total of 519 mothers, 360 pregnant and 159 postnatal, participated in the study with a response rate of $98.5 \%$. The mean age of the participants was 27.38 ( $\mathrm{SD}= \pm 4.7$ ). More than three-fourth of the participants' lived in an urban area. Most of the participants (86.13\%) followed Orthodox Christianity. About $37.96 \%$ of the participants level of education was college and above. Of the total participants, 357 $(68.79 \%)$ had at least one child (Table 1$)$.

\subsection{Obstetrics and medical-related factors of the participants}

An estimated $66.09 \%$ of the participants were multigravida. Of the total participants, $78.81 \%$ had planned pregnancies. About $94.41 \%$ of the participants had ANC visits for the index pregnancy. Of those more than half (56.53\%) have more than four visits for the last pregnancy. Mothers who had chronic disease during pregnancy or in the postpartum period were $15 \%$, among these, almost half $(7 \%)$ of those mothers had hypertension (Table 2 ).

\subsection{Knowledge and attitude about COVID-19 vaccination}

Our findings showed that $18.88 \%$ of the respondents scored $50 \%$ or more on the knowledge-related questions from a total score of five. The attitude of the respondents who scored $50 \%$ or more attitude assessing

Table 1

Socio-demographic characteristics of mothers in Central Gondar Zone, Northwest Ethiopia, $2021(\mathrm{n}=519)$.

\begin{tabular}{|c|c|c|c|}
\hline Variable & Response & Number & Percent \\
\hline \multirow[t]{3}{*}{ Age } & $18-25$ & 195 & 37.57 \\
\hline & $26-35$ & 290 & 55.88 \\
\hline & $36-48$ & 34 & 6.55 \\
\hline \multirow[t]{2}{*}{ Residence } & Urban & 409 & 78.81 \\
\hline & Rural & 110 & 21.19 \\
\hline \multirow[t]{3}{*}{ Religion } & Orthodox & 447 & 86.13 \\
\hline & Muslim & 68 & 13.10 \\
\hline & Protestant & 4 & 0.77 \\
\hline \multirow[t]{3}{*}{ Marital status } & Married & 510 & 98.27 \\
\hline & Divorced & 8 & 1.54 \\
\hline & Single & 1 & 0.19 \\
\hline \multirow[t]{4}{*}{ Educational status } & $\begin{array}{l}\text { No formal } \\
\text { education }\end{array}$ & 88 & 16.96 \\
\hline & primary education & 92 & 17.73 \\
\hline & $\begin{array}{l}\text { secondary } \\
\text { education }\end{array}$ & 142 & 27.36 \\
\hline & College and above & 197 & 37.96 \\
\hline \multirow[t]{2}{*}{ Academic area } & Health & 29 & 5.59 \\
\hline & Non-health & 490 & 94.41 \\
\hline \multirow[t]{7}{*}{ Occupation } & Hose wife & 224 & 43.16 \\
\hline & Private employee & 41 & 7.90 \\
\hline & $\begin{array}{l}\text { Government } \\
\text { employee }\end{array}$ & 160 & 30.83 \\
\hline & Merchant & 42 & 8.09 \\
\hline & Student & 40 & 7.71 \\
\hline & Daily laborer & 3 & 0.58 \\
\hline & Farmer & 9 & 1.73 \\
\hline \multirow[t]{5}{*}{ Husbands educational status } & $\begin{array}{l}\text { No formal } \\
\text { education }\end{array}$ & 60 & 11.56 \\
\hline & primary education & 98 & 18.88 \\
\hline & $\begin{array}{l}\text { secondary } \\
\text { education }\end{array}$ & 100 & 19.27 \\
\hline & College and above & 259 & 49.90 \\
\hline & $\begin{array}{l}\text { Mothers who were } \\
\text { single }\end{array}$ & 2 & 0.39 \\
\hline \multirow[t]{7}{*}{ Husbands occupation } & Farmer & 71 & 13.68 \\
\hline & Private employee & 107 & 20.62 \\
\hline & $\begin{array}{l}\text { Government } \\
\text { employee }\end{array}$ & 192 & 36.99 \\
\hline & Merchant & 106 & 20.42 \\
\hline & Student & 7 & 1.35 \\
\hline & Daily laborer & 35 & 6.75 \\
\hline & $\begin{array}{l}\text { Mothers who were } \\
\text { single }\end{array}$ & 1 & 0.19 \\
\hline \multirow[t]{2}{*}{ Do you have children } & Yes & 357 & 68.79 \\
\hline & No & 162 & 31.21 \\
\hline \multirow{3}{*}{$\begin{array}{l}\text { If you have a children how many } \\
\text { children do you have }\end{array}$} & $1-2$ & 254 & 71.15 \\
\hline & $3-4$ & 80 & 22.41 \\
\hline & $\geq 5$ & 23 & 6.44 \\
\hline
\end{tabular}


Table 2

Obstetrics and medical history of mothers in Central Gondar Zone, Northwest Ethiopia, 2021 ( $\mathrm{n}=519)$.

\begin{tabular}{|c|c|c|c|}
\hline Variable & Response & Number & percent \\
\hline \multirow[t]{2}{*}{ Maternal care type } & Antenatal care & 360 & 69.36 \\
\hline & Postnatal care & 159 & 30.64 \\
\hline \multirow[t]{2}{*}{ Gravidity } & Primigravid & 176 & 33.91 \\
\hline & multigravida & 343 & 66.09 \\
\hline \multirow[t]{3}{*}{ Parity } & Nully para & 25 & 4.82 \\
\hline & Primipara & 188 & 36.22 \\
\hline & Multipara & 306 & 58.96 \\
\hline \multirow{2}{*}{$\begin{array}{l}\text { Pregnancy planned for the } \\
\text { last pregnancy }\end{array}$} & Yes & 409 & 78.81 \\
\hline & No & 110 & 21.19 \\
\hline \multirow{2}{*}{ Do you have ANC visit } & Yes & 490 & 94.41 \\
\hline & No & 29 & 5.59 \\
\hline \multirow[t]{2}{*}{ Number of ANC visit } & $<4$ & 277 & 56.53 \\
\hline & $\geq 4$ & 213 & 43.47 \\
\hline \multirow{3}{*}{$\begin{array}{l}\text { Do you have PNC visit } \\
\text { (postnatal mothers) }\end{array}$} & Yes & 48 & 9.25 \\
\hline & No & 208 & 40.08 \\
\hline & ANC & 263 & 50.67 \\
\hline \multirow{2}{*}{$\begin{array}{l}\text { Had chronic disease (high } \\
\text { risk pregnancy) }\end{array}$} & Yes & 78 & 15.03 \\
\hline & No & 441 & 84.97 \\
\hline \multirow[t]{6}{*}{ Type of medical illness } & Hypertension & 37 & 7.13 \\
\hline & Diabetes & 17 & 3.28 \\
\hline & Anemia & 11 & 2.12 \\
\hline & Kidney problem & 1 & 0.19 \\
\hline & $\begin{array}{l}\text { Others (thyroid disease, } \\
\text { heart disease) }\end{array}$ & 12 & 2.31 \\
\hline & No illness & 441 & 84.97 \\
\hline
\end{tabular}

Table 3

Knowledge and attitudes of mothers in Central Gondar Zone, Northwest Ethiopia, 2021 ( $\mathrm{n}=519)$.

\begin{tabular}{|c|c|c|c|}
\hline Variables & Response & Number & Present \\
\hline \multirow{3}{*}{$\begin{array}{l}\text { Do you think that the COVID- } 19 \text { vaccine } \\
\text { carries the possibility of harm for your } \\
\text { baby }\end{array}$} & Yes & 210 & 40.46 \\
\hline & No & 160 & 30.83 \\
\hline & Uncertain & 149 & 28.7 \\
\hline \multirow[t]{3}{*}{ Vaccines have health related risk } & Yes & 148 & 28.52 \\
\hline & No & 178 & 34.30 \\
\hline & Uncertain & 193 & 37.19 \\
\hline \multirow{3}{*}{$\begin{array}{l}\text { Vaccines protect against infectious } \\
\text { disease }\end{array}$} & Yes & 103 & 19.85 \\
\hline & No & 153 & 29.48 \\
\hline & Uncertain & 263 & 50.67 \\
\hline \multirow{3}{*}{$\begin{array}{l}\text { Does the vaccines are easing the } \\
\text { complication of the disease? }\end{array}$} & Yes & 110 & 21.19 \\
\hline & No & 147 & 28.32 \\
\hline & Uncertain & 262 & 50.48 \\
\hline \multirow{3}{*}{$\begin{array}{l}\text { Dose vaccines produce long term- } \\
\text { immunity }\end{array}$} & Yes & 114 & 21.97 \\
\hline & No & 98 & 18.88 \\
\hline & Uncertain & 307 & 59.15 \\
\hline \multirow[t]{2}{*}{ Knowledge } & $\begin{array}{l}\text { Good } \\
\text { knowledge }\end{array}$ & 98 & 18.88 \\
\hline & $\begin{array}{l}\text { Poor } \\
\text { knowledge }\end{array}$ & 421 & 81.12 \\
\hline \multicolumn{4}{|l|}{ Attitudes towards the vaccine } \\
\hline \multirow[t]{3}{*}{ Do you believe vaccines are safe } & Yes & 150 & 28.90 \\
\hline & No & 114 & 21.97 \\
\hline & uncertain & 255 & 49.13 \\
\hline \multirow{3}{*}{$\begin{array}{l}\text { Do you think that, COVID-19 vaccines are } \\
\text { essential }\end{array}$} & Yes & 197 & 37.96 \\
\hline & No & 89 & 17.15 \\
\hline & uncertain & 233 & 44.89 \\
\hline \multirow{3}{*}{$\begin{array}{l}\text { In the event that you have covid-19, are } \\
\text { you ready to tell for your friends and } \\
\text { relatives }\end{array}$} & Yes & 437 & 84.20 \\
\hline & No & 55 & 10.59 \\
\hline & uncertain & 27 & 5.20 \\
\hline \multirow{3}{*}{$\begin{array}{l}\text { Was there any change in your point of } \\
\text { view positively towards vaccination in } \\
\text { general recently? }\end{array}$} & Yes & 285 & 54.91 \\
\hline & No & 141 & 27.17 \\
\hline & Uncertain & 93 & 17.92 \\
\hline \multirow{3}{*}{$\begin{array}{l}\text { We cannot decrease the frequency of } \\
\text { COVID-19 without vaccination }\end{array}$} & Yes & 96 & 18.50 \\
\hline & No & 391 & 75.34 \\
\hline & uncertain & 32 & 6.17 \\
\hline \multirow[t]{2}{*}{ Attitude } & $\begin{array}{l}\text { Favorable } \\
\text { attitude }\end{array}$ & 200 & 38.54 \\
\hline & $\begin{array}{l}\text { Unfavorable } \\
\text { attitude }\end{array}$ & 319 & 61.46 \\
\hline
\end{tabular}

items was $38.54 \%$ from the total score of five (Table 3).

\subsection{Intention to accept COVID-19 vaccine}

Of the total participants, $62.04 \%$ (95\% CI: 57.65-66.25) were willing to accept COVID-19 vaccine if it is available in Ethiopia. Of those participants, 208 (40.08\%) pregnant and 114 (21.97\%) postpartum mothers were willing to accept COVID-19 vaccine. About $81.89 \%$ of the participants got information about COVID-19 vaccines. An estimated $37.96 \%$ of participants got information from health care providers (Table 4).

\subsection{Concerns of mothers about COVID-19 vaccine}

In this study, the most common reason for COVID-19 vaccine hesitancy was religious beliefs $93(46.73 \%)$ and fear of affecting their fetus or baby 83 (41.71\%) (Fig. 1).

\subsection{Factors associated with COVID-19 vaccine acceptance}

The association between all potential independent variables towards COVID-19 vaccine acceptance was analyzed using binary logistic regression. Accordingly, in the bi-variable logistic regression analysis, predictor variables include age, residence, educational status, academic area, worry about COVID-19 disease, information exposure about covid19 vaccines, and attitude towards a vaccine. After controlling for confounders in a multivariable logistic regression analysis, residence, attitude towards vaccine, and worry about COVID-19 disease were significantly associated with COVID-19 vaccine.

Respondents living urban areas were 2.03 times more likely to accept COVID-19 vaccine than rural residents (AOR $=2.03 ; 95 \%$ CI: 1.09-3.77). Respondents who were worried about COVID-19 disease were 3.46 times more likely to accept COVID-19 vaccines than their counterparts (AOR $=3.46 ; 95 \%$ CI: 2.16-5.52). Furthermore, study participants who had favorable attitudes were 8.54 times more likely to accept COVID-19 vaccine than respondents who had unfavorable attitudes (AOR = 8.54; 95\% CI: 5.18-14.08) (Table 5).

\section{Discussion}

COVID-19 vaccination is a safe and effective approach to control the pandemic. Therefore, this study aimed to assess the prevalence of COVID-19 vaccine acceptance and the factors associated with it.

This study revealed that the overall COVID-19 vaccine acceptance was $62.04 \%$ (95\% CI: 57.65, 66.25). This study was comparable with a study conducted in Durban, South Africa $63.3 \% .^{18}$ However, the result

Table 4

Intent to accept a COVID-19 vaccine of mothers in Central Gondar Zone, Northwest Ethiopia, $2021(\mathrm{n}=519)$.

\begin{tabular}{llll}
\hline Variables & Response & Number & Present \\
\hline If vaccine is available for COVID-19 are & Yes & 322 & 62.04 \\
you willing to take it & No & 197 & 37.96 \\
Do you worry about COVID-19 disease & Yes & 297 & 57.23 \\
& No & 222 & 42.78 \\
Do you get information about COVID- & Yes & 425 & 81.89 \\
19 vaccines & No & 94 & 18.11 \\
If yes what are your source of & Health care & 197 & 37.96 \\
information about COVID-19 & providers & & \\
vaccine & Health extension & 81 & 15.61 \\
& workers & & \\
& Government & 66 & 12.72 \\
& Media (television/ & 345 & 66.47 \\
& radio) & & \\
& Internet & 55 & 10.60 \\
& Family members/ & 168 & 32.37 \\
& friends & & \\
\hline
\end{tabular}




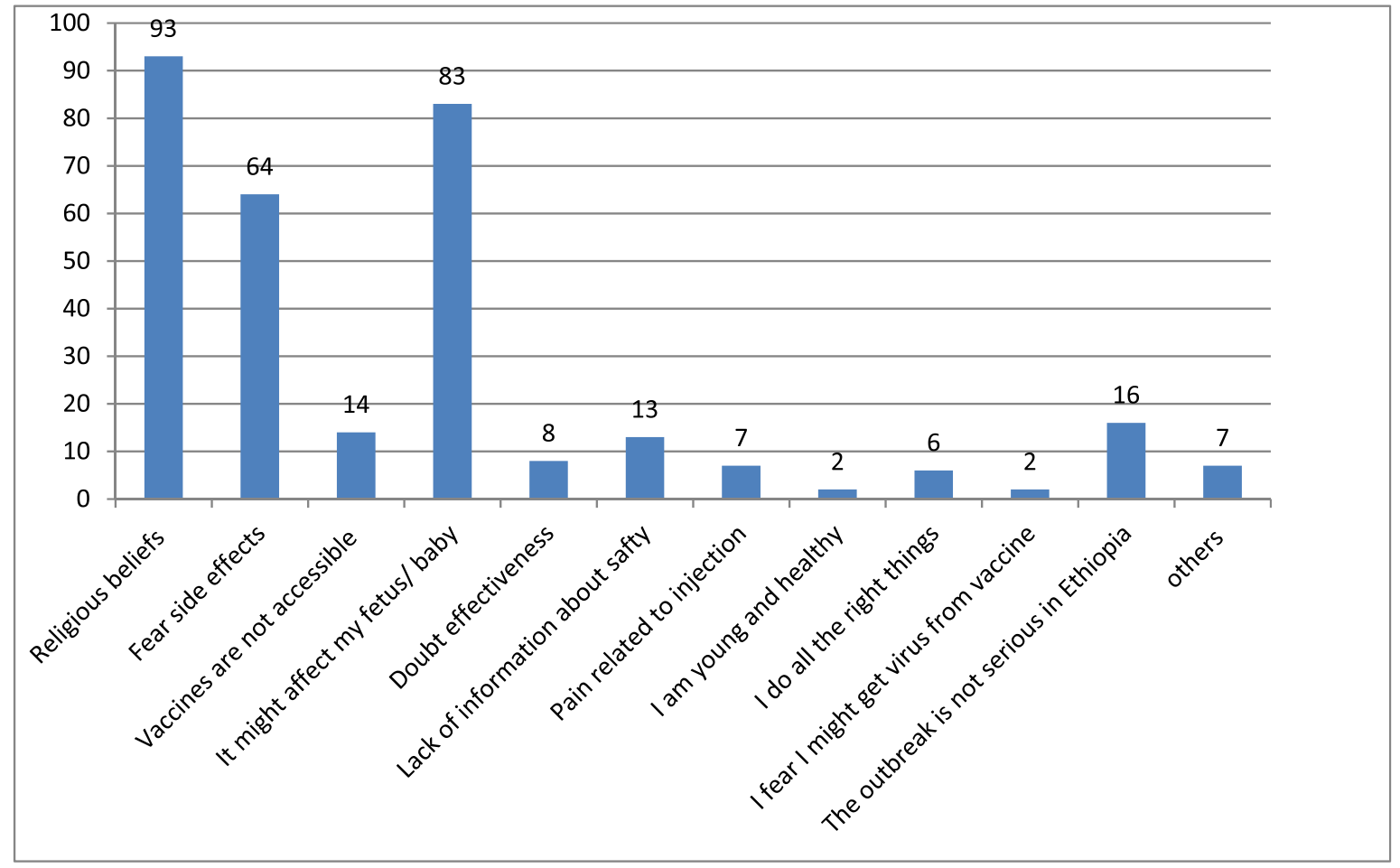

Fig. 1. Concerns of mothers about COVID-19 vaccine in Central Gondar Zone, Northwest Ethiopia, 2021.

Table 5

Bi-variable and multi-variable logistic regression of respondents in Central Gondar Zone, Northwest Ethiopia, 2021 ( $\mathrm{n}=519)$.

\begin{tabular}{|c|c|c|c|c|c|}
\hline \multirow[t]{2}{*}{ Variables } & & \multicolumn{2}{|c|}{$\begin{array}{l}\text { Vaccine } \\
\text { acceptance }\end{array}$} & \multirow[t]{2}{*}{$\begin{array}{l}\text { COR with } \\
95 \% \mathrm{CI}\end{array}$} & \multirow[t]{2}{*}{$\begin{array}{l}\text { AOR with } \\
95 \% \text { CI }\end{array}$} \\
\hline & & yes & No & & \\
\hline \multirow[t]{3}{*}{ Age } & $18-25$ & 122 & 73 & $\begin{array}{l}2.38(1.14 \\
5.01)\end{array}$ & $\begin{array}{l}1.5(0 \\
.62,3.61)\end{array}$ \\
\hline & $26-35$ & 186 & 104 & $\begin{array}{l}2.55(1.24 \\
5.27)^{*}\end{array}$ & $\begin{array}{l}1.81(0 \\
.79,4.13)\end{array}$ \\
\hline & $36-48$ & 14 & 20 & 1 & 1 \\
\hline \multirow[t]{2}{*}{ Residence } & Urban & 267 & 142 & $\begin{array}{l}1.88(1.23 \\
2.88)^{* *}\end{array}$ & $\begin{array}{l}2.03 \\
(1.09 \\
3.77)^{*}\end{array}$ \\
\hline & Rural & 55 & 55 & 1 & 1 \\
\hline \multirow[t]{4}{*}{ Educational status } & $\begin{array}{l}\text { No formal } \\
\text { education }\end{array}$ & 47 & 41 & 1 & 1 \\
\hline & $\begin{array}{l}\text { primary } \\
\text { education }\end{array}$ & 57 & 35 & $\begin{array}{l}1.42(.78, \\
2.57)\end{array}$ & $\begin{array}{l}0.94(0 \\
.42,2.11)\end{array}$ \\
\hline & $\begin{array}{l}\text { secondary } \\
\text { education }\end{array}$ & 81 & 61 & $\begin{array}{l}1.16(.68, \\
1.98)\end{array}$ & $\begin{array}{l}0.65(0 \\
.30,1.38)\end{array}$ \\
\hline & $\begin{array}{l}\text { College and } \\
\text { above }\end{array}$ & 137 & 60 & $\begin{array}{l}1.99(1.19 \\
3.34)^{* *}\end{array}$ & $\begin{array}{l}1.16 \\
(0.54 \\
2.53)\end{array}$ \\
\hline \multirow[t]{2}{*}{ Academic area } & Health & 23 & 6 & $\begin{array}{l}2.45(0.98 \\
6.12)\end{array}$ & $\begin{array}{l}2.04(0 \\
.71,5.84)\end{array}$ \\
\hline & Non- health & 299 & 191 & 1 & 1 \\
\hline \multirow[t]{2}{*}{$\begin{array}{l}\text { Do you worry about } \\
\text { COVID-19 disease }\end{array}$} & Yes & 103 & 119 & $\begin{array}{l}1.87 \\
(1.30,2.68) \\
* *\end{array}$ & $\begin{array}{l}3.46 \\
(2.16 \\
5.52) * *\end{array}$ \\
\hline & No & 94 & 103 & 1) & 1 \\
\hline \multirow{2}{*}{$\begin{array}{l}\text { Do you get } \\
\text { information } \\
\text { about COVID-19 } \\
\text { vaccines }\end{array}$} & Yes & 272 & 153 & $\begin{array}{l}1.56(1.00, \\
2.46)\end{array}$ & $\begin{array}{l}0.91 \\
(0.53 \\
1.56)\end{array}$ \\
\hline & No & 50 & 44 & 1 & 1 \\
\hline \multirow[t]{2}{*}{ Attitude } & $\begin{array}{l}\text { Favorable } \\
\text { attitude }\end{array}$ & 170 & 152 & $\begin{array}{l}6.23(3.99 \\
9.73)^{* *}\end{array}$ & $\begin{array}{l}8.54 \\
(5.18 \\
14.08)^{* *}\end{array}$ \\
\hline & $\begin{array}{l}\text { Unfavorable } \\
\text { attitude }\end{array}$ & 30 & 167 & 1 & 1 \\
\hline
\end{tabular}

$*=p$ value $<0.05$ and $* *=p$ value $\leq 0.01$ of this study was lower than studies conducted in China (77.4\%), ${ }^{19}$ Qatar (75\%), ${ }^{20}$ and Ethiopia $(70.7 \%) .{ }^{15}$ The possible reason for the study conducted in Qatar is; that study was an online cross-sectional study that may incorporate persons who had media exposure and may have high level of awareness. But, this study was conducted by a face-to-face interviewer-administered questionnaire. The possible difference in the study conducted in China was due to high sample size and may have better access to information.

This finding is higher than studies conducted in six European countries (40-50\%), ${ }^{14}$ a survey in 16 different countries (52\%), ${ }^{21}$ in Ankara City Hospital (37\%), ${ }^{22}$ Southwest Ethiopia $31.3 \%,{ }^{23}$ and in Switzerland (35.7\%). ${ }^{24}$ The possible reason may be the difference in the study period between our study and that of the others. Over the course of time, community's vaccine acceptance levels might change due to the availability of information and guidelines about COVID-19 vaccine for pregnant and lactating mothers.

This study identified that residence, being worried about COVID-19 disease, and attitude towards vaccines had a statistically significant association with COVID-19 vaccine acceptance. Accordingly, mothers in the urban residence were 2.03 times more likely to accept COVID-19 vaccine than rural ones. This study is supported by studies conducted in southwest Ethiopia. ${ }^{23}$ The possible justification might be in the urban residence there is an exposure to different social Medias; which is easy to gain information about COVID-19 vaccine.

The other statistically significant factor in this study was respondents' worry about COVID-19 disease. In this regard, respondents who worried about COVID-19 disease were 3.46 times more likely to accept COVID-vaccine than their counterparts. This study is supported by a study conducted in different countries. ${ }^{21}$ The possible reason might be respondents may acquire more information about the illness and how to prevent it. In addition, respondents who worried about COVID-19 disease may focus on preventive measures like vaccination to minimize their worries.

Finally, the other significant factor was attitudes towards vaccines. Respondents who had a favorable attitude towards the vaccine were 8.54 times more likely to accept COVID-19 vaccine than respondents 
who had an unfavorable attitude. This result is supported by studies conducted in 16 different countries ${ }^{21}$ and South Africa. ${ }^{18}$ The possible explanation might be the respondents who had a favorable attitude may trust the science of vaccines and observe the instructions given from different guidelines. The other reason might be; respondents who have favorable attitude towards the vaccine may accept the vaccine due to high desire and willingness to prevent the disease.

In Ethiopia, the burden of COVID-19 is high in all aspects especially it increases the burden on the health sector and many lives were lost due to the pandemic. To relieve the impact of the pandemic, vaccination is one of the best options. The public health importance of this study is to show the factors of COVID-19 vaccine acceptance among pregnant and postnatal mothers to take measure of preventing of COVID-19 disease and its complications. The other importance of this study is to provide information for health professionals, managers, stakeholders, and communities about factors that are associated with COVID-19 vaccine acceptance and to act on them to minimize the risk of COVID-19 and maximize their effort on prevention.

\section{Limitation of the study}

This study was cross-sectional, a design that does not permit establishing cause-effect relationships. In addition, due to intervieweradministered nature of the data collection process, there might be a possibility of social desirability bias being introduced in this study. In Ethiopia, there is no standardized tool and the tool for this study was adapted from different literatures which may have socio-economic, cultural, and health literacy differences. Even though the questionnaire was pre-tested before the start of actual data collection, still there may have limitations.

\section{Conclusion}

In this study, the willingness to accept COVID-19 vaccination was low. Residence, worry about COVID-19 disease, and attitudes towards vaccine were factors significantly associated with COVID-19 vaccine acceptance. Evidence-based and tailored information on COVID-19 vaccines should be provided to pregnant and postnatal mothers for both rural and urban residences to improve attitude towards COVID-19 vaccines and increase vaccination rates.

\section{Ethics approval and consent to participate}

Ethical clearance was obtained from the Institutional Review Board (IRB) of the University of Gondar (VP/RTT/05/2924/2021) and a letter of support was gained from the Central Gondar Zone health office and each Hospital administrates. Written consent was obtained from study subjects. For confidentiality purpose the names of patients were not included in the questionnaire. Furthermore, appropriate infection prevention practices and principles related to COVID-19 were considered during the data collection process.

\section{Consent for publication}

Not applicable.

\section{Data sharing statements}

The datasets collected and analyzed for this study are available from the principal investigator and can be attained on a reasonable request.

\section{Funding statement}

There is no funding for this work.

\section{Authors' contributions}

All the authors had significant involvement in the conception and designing the study, acquisition of data, analysis, and interpretation of data, took part in drafting the article, revising the article, gave final approval of the version to be published, have agreed on the journal to which the article has been submitted and agree to be accountable for all aspects of the work.

\section{Authorship \& conflicts of interest statement}

Manuscript title: COVID-19 vaccine acceptance and associated factors among women's in antenatal and postnatal care at Central Gondar Zone, Northwest Ethiopia, 2021.

Category 1.

Conception and design of study: Eden Bishaw Taye, Zewdu Wasie Taye, Haymanot Alem Muche, Nuhamin Tesfa Tsega, Tsion Tadesse Haile, and Agumas Eskezia Tiguh.

Acquisition of data: Eden Bishaw Taye, Zewdu Wasie Taye, Haymanot Alem Muche, Nuhamin Tesfa Tsega, Tsion Tadesse Haile, and Agumas Eskezia Tiguh.

Analysis and/or interpretation of data: Eden Bishaw Taye, Zewdu Wasie Taye, Haymanot Alem Muche, Nuhamin Tesfa Tsega, Tsion Tadesse Haile, and Agumas Eskezia Tiguh.

Category 2, Drafting the manuscript: Eden Bishaw Taye, Zewdu Wasie Taye, Haymanot Alem Muche, Nuhamin Tesfa Tsega, Tsion Tadesse Haile, and Agumas Eskezia Tiguh, Revising the manuscript critically for important intellectual content: Eden Bishaw Taye, Zewdu Wasie Taye, Haymanot Alem Muche, Nuhamin Tesfa Tsega, Tsion Tadesse Haile, and Agumas Eskezia Tiguh Category 3.

Approval of the version of the manuscript to be published (the names of all authors must be listed):

Eden Bishaw Taye, Zewdu Wasie Taye, Haymanot Alem Muche, Nuhamin Tesfa Tsega, Tsion Tadesse Haile, and Agumas Eskezia Tiguh.

\section{Declaration of competing interest}

The authors declare that we have no competing interests.

\section{Acknowledgments}

We would like to thank the University of Gondar for giving us ethical clearance. We deeply appreciate the data collectors and the study participants. Finally, we would like to thank Dr. Belaynew Wassie Taye (MD, MPh, Associate Prof. PHD candidate) for his guidance and editing this manuscript.

\section{References}

1 Diseases TLI. COVID-19, a pandemic or not? [Internet]. 2020/03/13 Lancet Infect Dis. 2020 Apr;20(4):383. Available from https://pubmed.ncbi.nlm.nih.gov/32178762.

2 Lazarus JV, Ratzan SC, Palayew A, et al. A global survey of potential acceptance of a COVID-19 vaccine. Nat Med. 2021;27(2):225-228.

3 Organization WH. COVID-19 Weekly Epidemiological Update, Edition. 58. 21 September 2021, 2021.

4 Africa CDC. Outbreak Brief \#89: Coronavirus Disease 2019 (COVID-19) Pandemic. 2021.

5 Organization WH. Weekly bulletin on outbreak and other emergencies: week. 44. November 2021:25-31, 2021.

6 Gray KJ, Bordt EA, Atyeo C, et al. COVID-19 vaccine response in pregnant and lactating women: a cohort study. Am J Obstet Gynecol. 2021.

7 Riley LE, Jamieson DJ. Inclusion of Pregnant and Lactating Persons in COVID-19 Vaccination Efforts. American College of Physicians; 2021.

8 Sculli MA, Formoso G, Sciacca L. COVID-19 vaccination in pregnant and lactating diabetic women [Internet] Nutr Metabol Cardiovasc Dis; 2021. Available from: https://www.sciencedirect.com/science/article/pii/S0939475321001824.

9 Adhikari EH, Spong CY. COVID-19 vaccination in pregnant and lactating women. JAMA [Internet]. 2021 Mar 16;325(11):1039-1040. https://doi.org/10.1001/ jama.2021.1658. Available from:.

10 Alwan NA, Burgess RA, Ashworth S, et al. Scientific consensus on the COVID-19 pandemic: we need to act now. Lancet. 2020;396(10260):e71-e72. 
11 Nadanovsky P, Santos APP Dos. Strategies to deal with the COVID-19 pandemic. Braz Oral Res. 2020:34.

12 Organization WH. Coronavirus Disease (COVID-19): Vaccines. WHO; 2020 [Internet].

13 El-Elimat T, AbuAlSamen MM, Almomani BA, Al-Sawalha NA, Alali FQ. Acceptance and attitudes toward COVID-19 vaccines: a cross-sectional study from Jordan. PLoS One. 2021;16(4), e0250555.

14 Ceulemans M, Foulon V, Panchaud A, et al. Vaccine willingness and impact of the COVID-19 pandemic on women's perinatal experiences and practices-a multinational, cross-sectional study covering the first wave of the pandemic. Int $J$ Environ Res Publ Health. 2021;18(7):3367.

15 Mose A, Yeshaneh A. COVID-19 vaccine acceptance and its associated factors among pregnant women attending antenatal care clinic in southwest Ethiopia: institutionalbased cross-sectional study. Int J Gen Med. 2021;14:2385.

16 Brillo E, Tosto V, Gerli S, Buonomo E. COVID-19 vaccination in pregnancy and postpartum [Internet] J Matern Neonatal Med. 2021 May 16:1-20. https://doi.org/ 10.1080/14767058.2021.1920916. Available from.

17 Sutton D, D'Alton M, Zhang Y, et al. COVID-19 vaccine acceptance among pregnant, breastfeeding and non-pregnant reproductive aged women. Am J Obstet Gynecol MFM. 2021, 100403.
18 Hoque AM, Buckus S, Hoque M, Hoque ME, Van Hal G. COVID-19 vaccine acceptability among pregnant women at a primary health care facility in Durban, South Africa. Eur J Med Heal Sci. 2020;2(5).

19 Tao L, Wang R, Han N, et al. Acceptance of a COVID-19 vaccine and associated factors among pregnant women in China: a multi-center cross-sectional study based on health belief model. Hum Vaccines Immunother. 2021:1-10.

20 Mohan S, Reagu S, Lindow S, Alabdulla M. COVID-19 vaccine hesitancy in perinatal women: a cross sectional survey. J Perinat Med. 2021.

21 Skjefte M, Ngirbabul M, Akeju O, et al. COVID-19 vaccine acceptance among pregnant women and mothers of young children: results of a survey in 16 countries. Eur J Epidemiol. 2021;36(2):197-211.

22 Goncu Ayhan S, Oluklu D, Atalay A, et al. COVID-19 vaccine acceptance in pregnant women. Int J Gynecol Obstet. 2021.

23 Hailemariam S, Mekonnen B, Shifera N, et al. Predictors of pregnant women's intention to vaccinate against coronavirus disease 2019: a facility-based crosssectional study in southwest Ethiopia. SAGE open Med. 2021;9, 20503121211038456

24 Stuckelberger S, Favre G, Ceulemans M, et al. SARS-CoV-2 vaccine willingness among pregnant and breastfeeding women during the first pandemic wave: a crosssectional study in Switzerland. Viruses. 2021;13(7):1199. 